\title{
Mothers progressed through a 4 phase process to resume their own lives after having twins
}

\author{
Beck CT. Releasing the pause button: mothering twins during the first year of life. Qual Health Res 2002;12:593-608.
}

\author{
QUESTIONS: What fundamental social psychological problem do mothers of twins \\ encounter during the first year after delivery? What process do mothers of twins use to \\ overcome this problem?
}

\author{
Design \\ Grounded theory.

\section{Setting} \\ New England, USA.
}

\section{Participants}

16 married mothers (mean age 32 y) of twins (mean age $8 \mathrm{mo}$ ) who were recruited from a Parents of Multiples Group that met monthly at a medical centre. 15 mothers were Caucasian, and 1 was African-American. 10 mothers were primaparas, and 6 were multiparas.

\section{Methods}

Data were collected using participant observation during the monthly Parents of Multiples Group meetings for 10 months and during home visits with the mothers. The mothers also participated in unstructured interviews that lasted 40 minutes to 1 hour and were audiotaped. Constant comparison involved simultaneously collecting, coding, and analysing data. Sampling continued until categories of a substantive theory of mothering twins were saturated.

\section{Main findings}

Life on hold was the basic social psychological problem for mothers of twins during the first year after delivery. Mothers progressed through a 4 phase process to overcome this problem: draining power, pausing own life, striving to reset, and resuming own life. Mothers described the draining power phase as a period of unrelenting demands, sleep deprivation, being emotionally torn between 2 infants requiring attention, and having no time to care for themselves. As a result of draining power, mothers entered the second phase, pausing own life, during which they felt they had to surrender their own lives in order to cope. Mothers described a blurring of days when day and night were intertwined and each day was much the same. Additionally, mothers felt confined and lacked outside connection. During the striving to reset phase, mothers began to establish coping strategies involving planning and organisation. They established a routine by getting the twins on the same feeding and sleeping schedule; shifted priorities so that such tasks as cooking and housecleaning were not as important as before; marshalled help from family, friends, and healthcare professionals; and problem solved situations unique to mothering twins. Mothers also began to venture outside the home with the twins. The final phase of resuming own life was reached when mothers felt their lives were becoming manageable. This was characterised by such milestones as the twins sleeping through the night or beginning to feed themselves. During this phase mothers also described reaping the blessings of having twins.

\section{Conclusions}

During the year after delivering twins, mothers described their life as being on hold. Mothers progressed through a 4 phase process to resume their lives.

\section{COMMENTARY}

Over the past 2 decades the incidence of twin births has increased, in part because of in vitro fertilisation. ${ }^{1}$ Studies have identified potential sources of stress for parents of twins including perinatal complications, fatigue and lack of sleep, management of daily needs of the infants, loss of control over such factors as time and privacy, and lack of time for themselves. ${ }^{2-3}$ In order to deliver high quality care to families with twins, nurses must be aware of their unique problems and needs so that appropriate interventions can be designed.

Beck's study begins to address this knowledge gap. She collected rich data through multiple strategies including participant observation at monthly multiple birth support meetings over a 10 month period, observation of mothers with their twins in their homes, unstructured interviews with the mothers, and participation in the care of the twins. She created a theory using substantive and theoretical coding of the data, collected data until the categories of the substantive theory were saturated, and validated the emerging theory with parents at a multiple birth parent meeting.

Beck's research undoubtedly contributes to our understanding of the unique experiences of mothers of twins, but caution should be exercised in the interpretation and application of the study findings. The mothers in Beck's study were predominantly Caucasian, married, mature in age, educated, had uncomplicated pregnancies and deliveries, and most had attended a support group for parents of multiples. Not all mothers of multiples may share these qualities or have the support of a multiples group. Beck's sample included primiparas and multiparas as well as mothers of twins conceived spontaneously and through infertility treatments.

The next step may be to "test" Beck's theory on other samples of mothers of twins to ensure that it is transferable. Then, nurses can apply the theory to individual mothers, identifying the specific phase of the process each mother is working through at a given time. Nursing interventions need to be designed to target specific phases of this theory and need to be evaluated. Through further research, nurses will be better positioned to provide optimal care to multiple birth families.

Becky Palmer, RN, CNM, MN, PNC(C) Mother of 12 month old twins Doctoral candidate, School of Nursing University of British Columbia Vancouver, British Columbia, Canada

1 Delisi T. The rising number of multiple births. Journal of Newborn Nursing 1999;1:17-9.

2 Leonard L. Depression and anxiety disorders during multiple pregnancy and parenthood. I Obstet Gynecol .

3 Williams RL, Medalie JH. Twins: double pleasure or double trouble? Am Fam Physician 1994;49:869-76. 